\title{
OXIDATIVE STRESS STATUS DUE TO METAL EXPOSURE IN WELDING
}

\author{
By \\ ${ }^{1}$ Ananian F B, ${ }^{1}$ Helal S F, ${ }^{2}$ Rashed L A, ${ }^{1}$ Shehata R A \\ ${ }^{1}$ Department of Occupational and Environmental Medicine, ${ }^{2}$ Department of Biochemistry, \\ Faculty of Medicine, Cairo University. Egypt
}

\begin{abstract}
:
Introduction: Welding is the most common way of permanently joining metal parts. Several metals commonly present in welding fumes including $\mathrm{Cr}, \mathrm{Fe}, \mathrm{Mn}, \mathrm{Cd}$ and $\mathrm{Pb}$ which are capable of generating reactive oxygen species (ROS) resulting in oxidative stress which in turn leading to disease development. Aim of work: The main objective of this work was to detect the health effect of some metals present in welding fumes. Materials and Methods: A case-control study was carried out on two groups, an exposed group and a control group after taking consent from them. The exposed group consisted of fifty workers occupationally exposed to welding fumes of one of the private factories for Iron and Steel industry at El Asher Men Ramadan, their mean age was 20 to 55 years $(34.3 \pm 6.9)$ work shift was for $12 \mathrm{hrs} / 6$ days/ week. The control group included thirty male person were selected from the industrial medicine outpatient clinic in Kasr Al Aini hospital, who were never exposed to welding fumes matching for age 25 to 50 years $(34.5 \pm 5.8)$, sex, socioeconomic status and smoking habits. All individuals in both groups were examined after taking consent and interviewed using detailed questionnaire including present, past, family history and occupational history. Clinical examination was performed with special emphasis on chest examination. Ventilatory function tests $\left(\mathrm{FVC}, \mathrm{FEV}_{1}, \mathrm{FEV}_{1} / \mathrm{FVC}\right.$ and PEF) were done. Laboratory investigations were performed : determination of blood levels of the following metals (manganese, iron, lead, chromium and cadmium) and determination of serum level of Superoxide dismutase enzyme (SOD). Results: The prevalence of respiratory tract disorders were significantly higher among the welders (20\%)compared to the control group $(0 \%)$ and statistically significant reduction in values of ventilator $y$ function parameters among the exposed workers compared to control group. The levels
\end{abstract}


of metals showed statistically significant increase among the exposed group more than the control group and statistically significant decrease of superoxide dismutase enzyme level among the exposed group compared to the control group. Conclusion: the level of superoxide dismutase enzyme (SOD) can be a useful biomarker for oxidative status after exposure to welding.

Key Words: Welders - Blood metals level changes - Superoxide dismutase - oxidative status

\section{Introduction}

Welding generates fumes that may contain many toxic materials, including several metals (e.g., cadmium [Cd], chromium $[\mathrm{Cr}]$, iron $[\mathrm{Fe}]$, lead $[\mathrm{Pb}]$, manganese $[\mathrm{Mn}]$, and nickel [Ni]), and toxic gases (e.g., carbon monoxide, ozone, and nitrogen oxides) (Antonini, 2003). These metals and gases have the potential to produce adverse health effects in welders (Li et al., 2005).

The increased generation of Reactive oxygen species(ROS) produced by chromium $(\mathrm{Cr})$, lead $(\mathrm{Pb})$, iron $(\mathrm{Fe})$ and manganese $(\mathrm{Mn})$, has been shown to disrupt biochemical homeostasis, resulting in lipid peroxidation, DNA damage, depletion of sulfhydryls, and altered calcium homeostasis (Stohs and Bagchi, 1995).

Depletion of the primary antioxidant defenses; antioxidant enzymes (superoxide dismutase, catalase and glutathione peroxidase), and the inability of welders to overcome the increased oxidant generation may facilitate disease development (Halliwell and Gutteridge, 1990).

The oxidative stress status can be detected through determination of the serum levels of superoxide dismutase enzyme and /or serum malondialdehyde (the biomarkers of oxidative stress status).

\section{Aim of Work}

The main objective of this work was to detect the health effect of some metals present in welding fumes.

\section{Materials and Methods}

A case-control study was carried out on two groups, an exposed and a control group after taking consent from them. The exposed group consisted of fifty workers occupationally exposed to welding fumes of one of the private factories for Iron and Steel industry at El Asher Men Ramadan.

All of them were male; their mean age was $34.3 \pm 6.9$ years ranging from 
20 to 55 years .Direction of welding related work shift was for $12 \mathrm{hrs} /$ day for all workers. They worked under various conditions such as semi enclosed or open areas. Most of the workers sometimes wore specific mask respirators.

The control group included thirty male person were selected from outpatient clinic in Kasr Al Aini hospital, who were never exposed to welding fumes and without respiratory affection taking into consideration matching of age ,sex, socioeconomic status and smoking habits. Their mean age was $34.5 \pm 5.8$ ranging from 25 to 50) years.

Both groups were subjected to the following:

- Detailed history was taken stressing: Personal, Occupational, Medical, Present and Past history.

- Clinical examination stressing on chest examination .Spirometric measurements was done using a portable calibrated spirometer (vitalographBuckingham, England). The American Thoracic Society standards for testing were followed and the best three trials for all parameters were obtained.

- Laboratory investigations:
1- Determination of superoxide dismutase blood level (SOD):

Superoxide dismutase was measured in whole blood sample by colorimetric method using kit supplied by Dojindo molecular technology. SOD Assay Kit-WST allows very convenient SOD assaying by utilizing Dojindo's highly water-soluble tetrazolium salt that produces a water-soluble formazan dye upon reduction with a superoxide anion. The rate of the reduction with O2.-are linearly related to the xanthine oxidase (XO) activity, and is inhibited by SOD, Therefore, the IC50 (50\% inhibition activity of SOD or SODlike materials) can be determined by a colorimetric method (Patent filing).

2- Determination of chromium, cadmium, lead, manganese, iron levels in the blood samples:

Serum chromium and blood cadmium were measured by graphite furnace atomic absorption spectrophotometer with Zeeman background (Thermo elemental M-6 type).

Serum iron, manganese and blood lead levels were measured by flame furnace atomic absorption spectrophotometer with Deuterium 
background (Thermo elemental M-6 type).

For reading metals concentration of both sample and standard (calibrator), first it was important to choose proper wave length, lamp current band pass optimization for each metal.

Calculation of the results was done by plotting standard curve, the reading of absorbance of sample and calibrator was plotted in semilog curve, the concentration of each metal in samples were interpreted from this standard curve.

Normal values of Lead are from 30 to $40 \mathrm{ug} / \mathrm{dl}$, for cadmium are $<3 \mathrm{ug} / \mathrm{l}$, for manganese are from 0.5 to $2 \mathrm{ug} / 1$, for chromium are from 0.5 to $5 \mathrm{ug} / 1$ and for iron are from 60 to $150 \mathrm{ug} / \mathrm{l}$ (Andrew, 1998)

\section{Results}

Table (1): Serum metals levels and the level of super oxide dismutase among the studied groups.

\begin{tabular}{|l|c|c|c|c|c|c|}
\hline \multirow{2}{*}{ The examined group } & \multicolumn{2}{|c|}{$\begin{array}{c}\text { Exposed } \\
(\mathbf{n = 5 0})\end{array}$} & \multicolumn{2}{c|}{$\begin{array}{c}\text { Control } \\
(\mathbf{n = 3 0})\end{array}$} & t-test & p-value \\
\hline Different investigations & Mean & \pm SD & Mean & + +SD & & \\
\hline Pb Blood level $(30-40 \mathrm{ug} / \mathrm{dl})$ & 81.62 & \pm 35.89 & 28.41 & \pm 9.41 & 7.93 & $<0.001^{*}$ \\
\hline Cd Serum level $(<3 \mathrm{ug} / \mathrm{l})$ & 3.22 & \pm 3.6 & 1.09 & \pm 0.64 & 3.18 & $<0.05$ \\
\hline Mn Serum level $(0.5-2 \mathrm{ug} / \mathrm{l})$ & 3.29 & \pm 2.13 & 2.89 & \pm 1.09 & 0.95 & $>0.05$ \\
\hline Cr Serum level $(0.5-5 \mathrm{ug} / \mathrm{l})$ & 6.92 & \pm 2.13 & 1.69 & \pm 1.03 & 12.56 & $<0.001 *$ \\
\hline Fe Serum level $(60-150 \mathrm{ug} / \mathrm{l})$ & 156.48 & \pm 122.6 & 81.51 & \pm 22.03 & 3.30 & $<0.001 *$ \\
\hline SOD blood level $(195-240 \mathrm{u} / \mathrm{ml})$ & 148.77 & \pm 30.22 & 255.38 & \pm 16.27 & -12.79 & $<0.001 *$ \\
\hline
\end{tabular}

*: Statistically significant $(\mathrm{p}<0.001)$.

Table 1 shows statistically significant differences between the exposed and the control groups as regards lead, cadmium, chromium, iron, and superoxide dismutase level in the blood of both groups $(\mathrm{p}<0.05)$. 


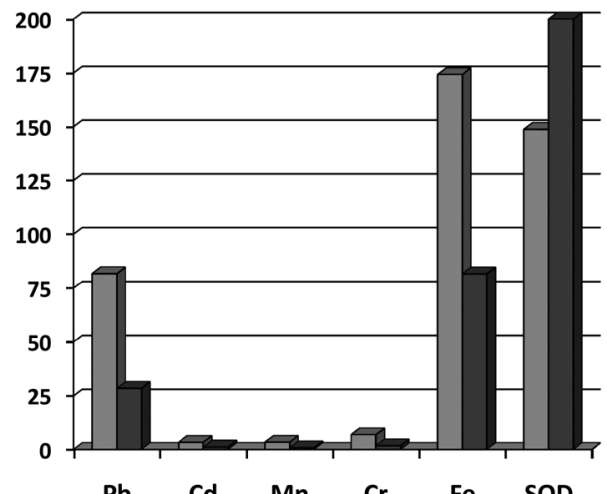

$\square$ Mean of exposed

$\square$ Mean of control

Fig(1): Serum metals levels and the level of super oxide dismutase among the studied groups.

Table 2: Comparison between the exposed and the control groups as regard the ventilatory function tests

\begin{tabular}{|l|c|c|c|c|c|c|}
\hline & $\begin{array}{c}\text { Exposed } \\
(\mathbf{n}=50)\end{array}$ & $\begin{array}{c}\text { Control } \\
(\mathbf{n}=\mathbf{3 0})\end{array}$ & $\mathbf{t}$-test & $\mathbf{p}$-value & & \\
\hline & Mean & \pm SOD & Mean & $\mathbf{\pm S O D}$ & & \\
\hline FVC \% & 74.04 & \pm 6.70 & 91.06 & \pm 5.87 & -11.50 & $<0.001^{*}$ \\
\hline FEV1\% & 65.22 & \pm 5.50 & 86.10 & \pm 5.96 & -15.90 & $<0.001^{*}$ \\
\hline FEV1/FVC & 76.96 & \pm 6.84 & 93.63 & \pm 5.64 & -11.23 & $<0.001^{*}$ \\
\hline PEF\% & 61.30 & \pm 7.24 & 84.66 & \pm 3.59 & -16.47 & $<0.001^{*}$ \\
\hline
\end{tabular}

*: Statistically significant $(\mathrm{p}<0.001)$.

Table 2 showed a statistical significant difference between the exposed and the control groups as regard ventilatory function parameters $(\mathrm{p}<0.001)$. 


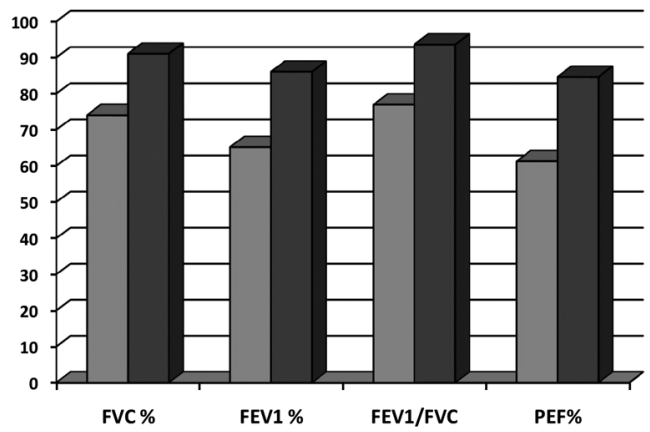

Mean of Exposed

aMean of Control

Fig (2): Comparison between the exposed and the control groups as regard the ventilatory function tests.

Table 3: Prevalence of bronchial asthma among the studied group

\begin{tabular}{|c|c|c|c|c|c|c|}
\hline & \multirow{2}{*}{\multicolumn{2}{|c|}{$\begin{array}{l}\text { Exposed } \\
(n=50)\end{array}$}} & \multirow{2}{*}{\multicolumn{2}{|c|}{$\begin{array}{l}\text { Control } \\
(n=30)\end{array}$}} & \multirow{3}{*}{$\begin{array}{c}\text { Fischer's } \\
\text { test }\end{array}$} & \multirow{3}{*}{ p-value } \\
\hline & & & & & & \\
\hline & $\mathrm{N}$ & $\%$ & $\mathrm{~N}$ & $\%$ & & \\
\hline $\begin{array}{l}\text { Asthma (Cough, dyspnea and } \\
\text { wheezy chest) }\end{array}$ & 10 & $20 \%$ & 0 & $0 \%$ & 10.24 & $<0.05^{*}$ \\
\hline
\end{tabular}

*: Statistically significant

Table 3 showed a high prevalence of asthma among the exposed group with statistically significant difference between the exposed and control groups.

Table 4: Correlation between the blood level of superoxide dismutase and different metals levels among welders

\begin{tabular}{|l|c|c|c|}
\hline & $\mathbf{r}$ & $\mathbf{F}$ & p-value \\
\hline $\mathbf{P b}$ & -0.09 & 0.52 & $>0.05$ \\
\hline $\mathbf{C d}$ & 0.03 & 0.8 & $>0.05$ \\
\hline $\mathbf{M n}$ & -0.10 & 0.46 & $>0.05$ \\
\hline $\mathbf{C r}$ & 0.30 & 0.03 & $<0.05^{*}$ \\
\hline $\mathbf{F e}$ & -0.06 & 0.66 & $>0.05$ \\
\hline
\end{tabular}

*: Statistically significant 
Table 4 showed negative correlations between the level of super oxide dismutase and the level of lead, manganese and iron, but didn $>$ reach the level of significance. This table demonstrates also that there was a positive correlation between the level of super oxide dismutase and the level of cadmium and chromium (statistically significant as regard the chromium and it didn>t reach the level of significance as regard the cadmium).

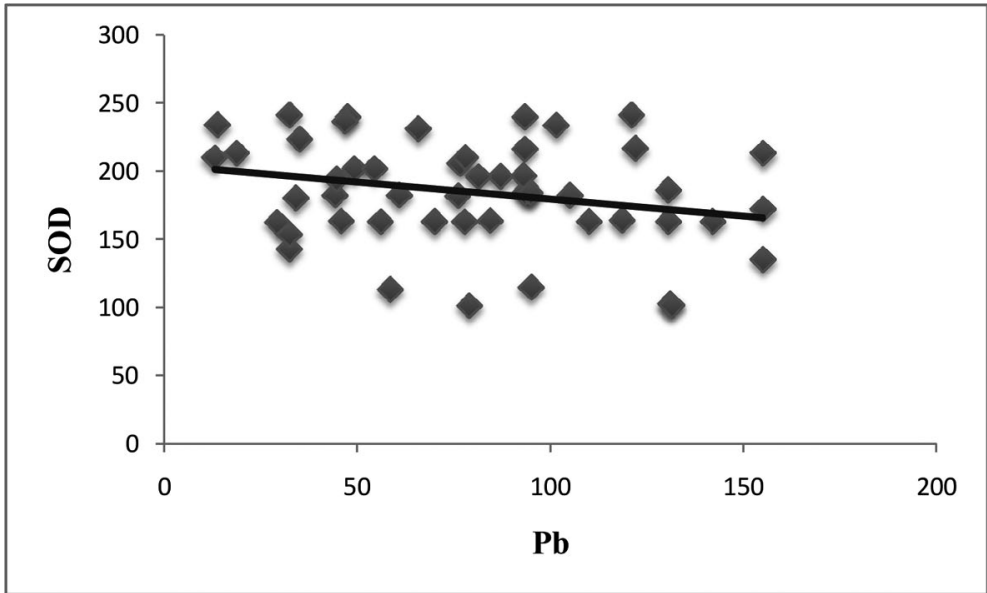

Fig (3): Correlation between the blood level of superoxide dismutase and lead.

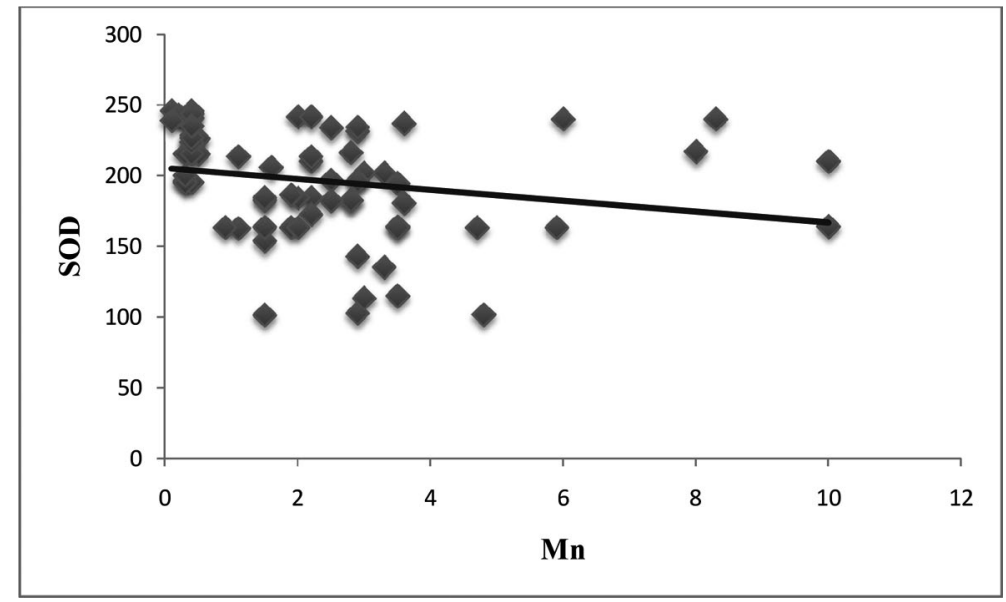

Fig (4): Correlation between the blood level of superoxide dismutase and manganese. 


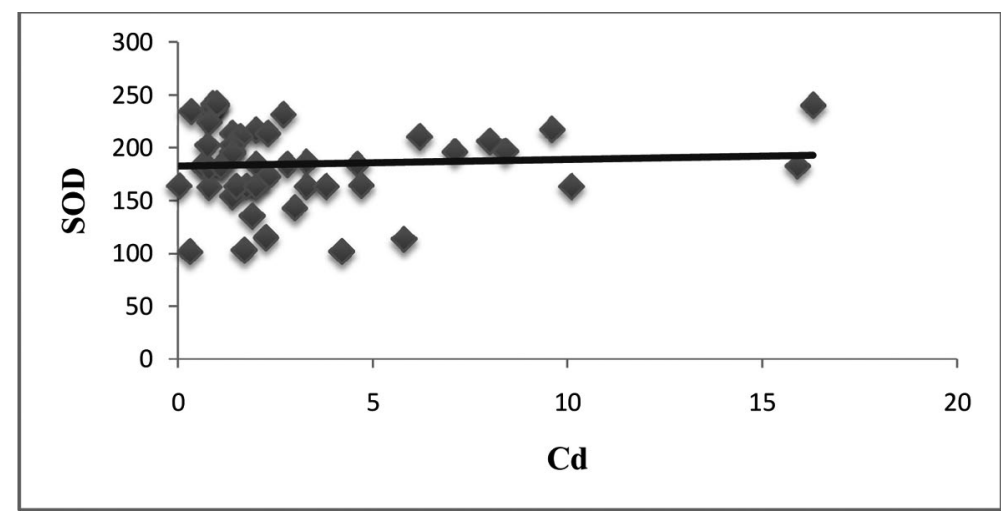

Fig (5): Correlation between the blood level of superoxide dismutase and cadmium

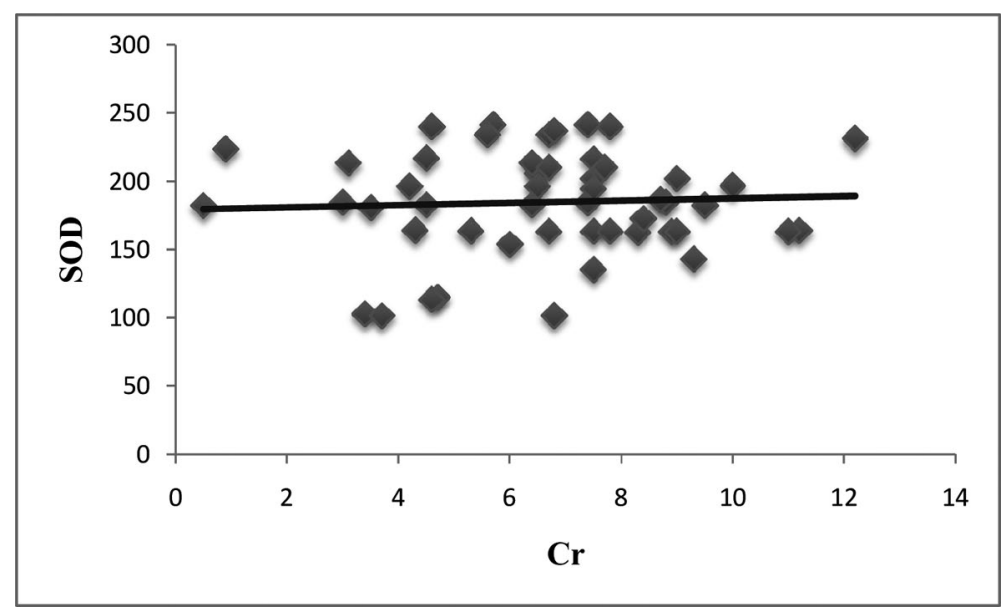

Fig (6): Correlation between the blood level of superoxide dismutase and chromium 
Table 5: Correlation between the level of super oxide dismutase and the ventilatory functions in the exposed group

\begin{tabular}{|l|c|c|c|}
\hline & $\mathrm{r}$ & $\mathrm{F}$ & $\mathrm{p}$-value \\
\hline FVC & 0.02 & 0.86 & $>0.05$ \\
\hline FEV1 & 0.07 & 0.60 & $>0.05$ \\
\hline FEV1/FVC & 0.10 & 0.46 & $>0.05$ \\
\hline PEF & 0.06 & 0.63 & $>0.05$ \\
\hline
\end{tabular}

Table 5 showed that there was a positive correlation between superoxide dismutase level at the exposed workers and their ventilatory function parameters that did not reach statistically significance at $\mathrm{p}>0.05$.

\section{Discussion}

This study reported that the blood level of lead, cadmium, manganese, chromium, iron and superoxide dismutase show statistically significant differences between the group exposed to welding fumes and the control group $(\mathrm{p}<0.05)$. The blood metal levels showed a statistically significant increase among the exposed group as $\quad(\mathrm{Pb}=81.6 \pm 35.8, \quad \mathrm{Mn}=3.2 \pm 2.1$, $\mathrm{Cr}=6.9 \pm 2.1$, $\mathrm{Fe}=156.4 \pm 17.3$, $\mathrm{Cd}=3.2 \pm 3.6)$ and showed a statistically significant reduction in the level of SOD $(=148.7 \pm 30.2)$ in the exposed group compared to the control group (Table1) (Fig1).
Edme and his collegues, (1997) reported in their study for assessing the level of chromium among 116 stainless steel welders using manual metal arc, metal inert gas and tungsten inert gas that there was a statistically significant differences between the group exposed to welding fumes and the control group as regards the total soluble chromium mainly hexavalent chromium.

Guojun and his coworkers, (2004) also reported that serum concentrations of manganese and iron as well as the blood lead concentration were statistically significantly higher among welders than in control subjects. Serum manganese concentrations in 
welders showed approximately four -fold increase as compared to control subjects, whereas the increases in levels of serum iron and blood lead were 1.9-fold and 2.6-fold, respectively. Blood SOD activities in welders were statistically significantly reduced as compared to the control group.

In contrast with our findings Sung and his collegues, (2005) illustrated that the antioxidant enzymes Glutathione peroxidase (GPX) and Superoxide dismutase (SOD) showed statistically significant increase in welders compared with unexposed subjects. They explained this increase by the fact that increased oxidative stress by welding fumes might stimulate the formation of more antioxidant enzymes to compensate the consumed SOD and other antioxidant enzymes, so it is possible that prolonged oxidant stress leads to an increase in these antioxidant enzymes.

Similar findings were reported by Li and his coworkers, (2004) that superoxide dismutase (SOD) enzyme and the erythrocyte catalase (CAT) activities were statistically significantly higher among welders which reflect the lipid peroxidation in the erythrocyte membrane.
The reduction of superoxide dismutase in our study may be due to prolonged exposure and/or heavy exposure to welding fumes as welding need more skills and long periods of working, so our measurement might be done at time when the positive feedback mechanism of the body was exhausted.

Our study showed that there was a highly statistically significant reduction in ventilatory functions among the exposed group compared to the control $(\mathrm{p}<0.05)$ that is to say means of $\mathrm{FVC} \%$, FEV1\%, FEV1/FVC\% and PEF\% as shown in (Table2) (Fig2). Our results are in agreement with those of Stepnewski et al, (2003) and those of Fatma et al., (2005) as they reported that forced expiratory volume in one second (FEV1)/forced vital capacity (FVC) and peak expiratory flow measured in the welding workers were statistically significantly lower than those in the control group.

By analyzing the clinical findings of the exposed workers in the present study as regards bronchial asthma symptoms (dyspnea, wheezes and productive cough) were the most common health problems, as shown in (Table3). The prevalence of respiratory disorders was statistically significantly higher among 
the exposed group when compared to the control group. Among the exposed workers, twenty (20\%) percent were suffering from attacks of bronchial asthma compared to zero $(0 \%)$ of the control group.

In agreement with these results, Antonini and his collegues, (2004) reported that a large number of welders experience the same type of respiratory illness included bronchitis, asthma, and a possible increase in the incidence of lung cancer.

Discussing our aim to find the relation between serum level of superoxide dismutase and blood level of lead, manganese, chromium, cadmium and iron, we found in (Table4) that there was a negative correlation between the blood level of SOD with levels of lead, manganese and iron; this means that elevation of these metals in blood is associated with decrease in the blood level of superoxide dismutase enzyme (Fig 3,4). Also that high levels of cadmium and chromium was not associated with reduction in the level of SOD as shown in Fig $(5,6)$.This may be due to the fact that liver, spleen and kidney accumulate the majority of chromium after prolonged exposure (Saner et al., 1984), also about half cadmium body burden is stored in liver and kidney after long term exposure (Kjellstrom, 1979).

Patil and his collegues, (2006) reported that lead exposed workers resulting in increase in lipid peroxidation associated with decrease in erythrocyteSOD and erythrocyte-catalase activities.

Sung and his coworkers, (2005) reported in their study that there were positive correlations between Mn levels in the blood of welders and Mn-SOD. They also reported a statistically positive correlations with blood $\mathrm{Pb}$ levels and Mn-SOD They explained their findings by the fact that blood levels of Mn and $\mathrm{Pb}$ are likely to be influenced by diet and environmental exposures.

We found in our work that there was positive correlation between superoxide dismutase blood level in the exposed group and their ventilatory function results that did not reach the level of significance $(p>0.05)$.It means that decrease in ventilatory function parameters was associated by decrease of SOD level (Table 5).

Stepnewski and his collegues (2003) in their study found that in the group of welders, the concentration of SOD was lower compared to controls. 
The incidence of extreme obstructive pulmonary disease and small airway disease in the welder group was more frequent than in controls. Changes in the concentration (or activity) of antioxidant parameters cannot be used as markers of ventilatory dysfunction; because these enzymes affected by many other factors.

Increased oxidative stress and decreased superoxide dismutase (SOD) activity are associated with airflow limitation and hyperactivity. Gaston and his coworkers, (1994) hypothesized that asthmatic individuals with higher levels of oxidative stress may have greater loss of SOD activity, which would be reflected systemically in loss of circulating SOD activity and clinically by development of severe asthma and/ or worsening airflow limitation.

\section{Conclusion}

On the basis of these results it is clear that occupational exposure to welding fumes is likely one of the major contributing factor in the changes of Superoxide dismutase enzyme. Therefore, quantitative measurements of markers of oxidative stress in the serum of welders may be valuable in monitoring changes caused by exposure to welding fumes (Sung et al., 2005).
From the findings of the present study, we recommend prospective studies using these biomarkers of oxidative stress combined with close clinical monitoring of disease to understand the mechanisms of welding related disease development and to assess whether there is a need for further reduction of workers exposure to welding fumes.

\section{References}

1. Andrew Taylor (1998): Trace Element External Quality Assessment Scheme. SAS Trace Elements Handbook; P 8-13

2. Antonini JM, Taylor MD, Zimmer AT and Roberts JR (2004): Pulmonary responses to welding fumes: role of metal constituents. J Toxicol Environ Health A; 67(3):233-49.

3. Antonini J (2003): (Health Effect of Welding) critical Review in toxicology; 33(1):61-103

4. Edmé J, Shirali P, Mereau M, Sobaszek A, Boulenguez C, Diebold F and Haguenoer J (1997): Assessment of biological chromium among stainless steel and mild steel welders in relation to welding processes. Int Arch Occup Environ Health; 70(4):237-42.

5. Fatma F, Mehmet Ü, Tülay K, Levent T, Sema A, Reha D and Mustafa S (2005): "OxidantAntioxidant Status and Pulmonary Function in Welding Workers". J Occup Health; 47: 286292

6. Gaston B, Drazen J, Loscalzo J and Stamler J (1994): The biology of nitrogen oxides in the airways. Am J Respir Crit Care Med; 149:538551.

7. Guojun JL, Long LZ, Ling L, Ping W and Wei Z (2004): Occupational Exposure to Welding Fume among Welders. JOEM; 46:241-248.

8. Halliwell B and Gutteridge J (1990): The 
antioxidants of human extracellular fluids. Arch Biochem Biophys; 280:1-8.

9. Kjellström T (1979): Exposure and accumulation of cadmium in populations from Japan, the United States and Sweden. Environ Health Perspect; 28:169-197.

10. Li GJ, Zhang LL, Lu L, Wu P and Zheng W (2005): Occupational exposure to welding fume among welders, Alteration of Manganese, Iron, Zinc, Copper and Lead in body fluids and oxidative stress status;P.241-248.

11. Li GJ, Zhang LL, Lu L, Wu P, Zheng W. (2004): Occupational exposure to welding fume among welders: alterations of manganese, iron, zinc, copper, and lead in body fluids and the oxidative stress status; J Occup Environ Med.; 46(3):241-8.

12. Patil AJ, Bhagwat VR, Patil JA, Dongre NN, Ambekar JG, Jailkhani R and Das KK (2006): Effect of lead $(\mathrm{Pb})$ exposure on the activity of superoxide dismutase and catalase in battery manufacturing workers (BMW) of Western Maharashtra (India) with reference to heme biosynthesis. Int J Environ Res Public Health; 3(4):329-37.

13. Saner G, Yuzbasiyan V and Cigdem S (1984): Hair chromium concentration and chromium excretion in tannery workers. Br. J. Ind. Med; 41:263-66.

14. Stepnewski M, Kolarzyk E, Pietrzycka A, Kitlinski M, Helbin J and Brzyszczan K (2003): Antioxidant enzymes and pulmonary function in steel mill welders. 16(1):41-7

15. Stohs SJ and Bagchi D (1995): Oxidative mechanisms in the toxicity of metal ions. Free Radic. Biol. Med; 18 (2): 321-36. PMID 7744317.

16. Sung G, Yangho K, Michael L, Donna L, Vincent C and Val V (2005): Correlates of Oxidative stress and Free radical activity in serum from Asymptomatic Shipyard Welders. Am J respire Crit care Med; 172: 1541-1548. 